\title{
A RELAÇÃO HOMEM-TRABALHO NO BRASIL CONTEMPORÂNEO E OS IMPACTOS DA COVID-r9: UM OLHAR DA TERAPIA COGNITIVO- COMPORTAMENTAL
}

\author{
THE MAN-WORK RELATIONSHIP IN CONTEMPORANY BRAZIL AND THE \\ IMPACTS OF COVID-I9: A VIEW OF COGNITIVE BEHAVIORAL THERAPY
}

\author{
Kátia Assis de Oliveira ${ }^{1}$ \\ Joice Cristina Cardoso da Silva ${ }^{2}$ \\ Silvia Helena Modenesi Pucci ${ }^{3}$
}

RESUMO: O trabalho é constituinte do ser humano. Sua falta pode ser motivo de adoecimento físico e psíquico. Nesta pesquisa recorta-se a problemática da falta de trabalho em três períodos da história do Brasil: a década de 1980 , em plena ditadura militar; os anos 2000, com a globalização e a informatização; e a partir de 2020 até a atualidade, com o contexto da pandemia de Covid-ı. Por meio da metodologia de estudo de caso, apresenta-se uma análise sob a óptica da Terapia Cognitivo-Comportamental, com o objetivo de verificar possibilidades de intervenção para prevenir a instalação de sintomas frente aos impactos negativos do evento. Considerando-se a cognição como mediadora do comportamento humano, essa leitura contribui para a reestruturação de pensamentos e crenças que estão na raiz do adoecimento do indivíduo. Tendo em vista que certos padrões cognitivos e comportamentais possam causar sofrimento ao ser humano, a presente pesquisa vem apoiar os profissionais da Psicologia no atendimento a indivíduos que estejam enfrentando o problema da falta de trabalho.

Palavras-chave: Trabalho. Desemprego. Covid-r9. Terapia Cognitivo-Comportamental.

\footnotetext{
${ }^{1}$ Graduada em Psicologia - Formação de Psicólogo e Bacharelado pela Universidade Santo Amaro UNISA. Especialista em Língua Portuguesa- UNISA. Especialista em Língua Brasileira de Sinais-UNISA. Licenciatura Plena em Letras - Português/Inglês -UNISA.

${ }^{2}$ Graduada em Psicologia formação de Psicólogo e Bacharelado pela Universidade Santo Amaro - UNISA.

${ }^{3}$ Doutora em Psicologia da Saúde pela Universidade do Minho, UMINHO - Portugal (com revalidação pela Universidade de Campinas / UNICAMP. Setor Medicina - Brasil. Pesquisadora Membro do Grupo de Estudos de Jovens Investigadores da Sociedade Portuguesa para o Estudo da Obesidade- SPEO. Pesquisadora Colaboradora no Grupo de Pesquisa da Universidade do Minho / Portugal. Processos Psicológicos Individuais e Familiares em Saúde e Doença. Mestre pelo Programa de Pós-Graduação em Psiquiatria e Psicologia Médica - UNIFESP. Especialista em Psico-Oncologia pelo Hospital do Câncer/ SP. Especialista em Dependência Química Universidade Federal de São Paulo/UNIFESP. Especialista em Promoção e Prevenção à Saúde em Álcool, Tabaco e Outras Drogas (UNIFESP). Coordenadora e Docente de Psicologia na Universidade Santo Amaro / UNISA - Brasil, em diversas disciplinas, bem como Supervisora hospitalar, Membro do NDE e atendimento junto alunos da Medicina - PAPU. Membro do Comitê de Ética e Orientadora de trabalhos científicos. Revisora de artigos Nacionais e Internacionais. (CV: http://lattes.cnpq.br/o913875901013757).
} 
ABSTRACT: Work is part of the human being. Its absence can be a reason for physical and mental illness. This research highlights the problem of lack of work in three periods of Brazilian history: the 1980s, during the military dictatorship; the 200os, with globalization and computerization; and from 2020 to the present, with the context of the Covid-I9 pandemic. Through the case study methodology, an analysis is presented from the perspective of Cognitive-Behavioral Therapy, with the objective of verifying possibilities of intervention to prevent the onset of symptoms against the negative impacts of the event. Considering cognition as a mediator of human behavior, this reading contributes to the restructuring of thoughts and beliefs that are at the root of the individual's illness. Bearing in mind that certain cognitive and behavioral patterns can cause suffering to human beings, this research supports Psychology professionals in assisting individuals who are facing the problem of lack of work.

Keywords: Work. Unemployment. Covid-ı. Cognitive-Behavioral Therapy.

\section{INTRODUÇÃO}

O trabalho é condição sine qua non para a constituição da humanidade (ENGELS, 1876). Não o ter ou ter de desempenhá-lo em condições precárias pode causar ao indivíduo formas diversas de adoecimento, tanto físico quanto psíquico (DEJOURS, 2015).

A TCC considera que, em geral, o comportamento humano é mediado pela cognição. Assim, propõe participação ativa de indivíduo e terapeuta na intervenção sobre padrões cognitivos e comportamentais que estejam causando sofrimento. (WENZEL, 2018)

Nesta pesquisa, visa-se a analisar a constância sócio-histórica da falta de trabalho para o indivíduo. Com esses dados, espera-se visualizar o que tem ocorrido ao longo do tempo nessa díade, bem como identificar, por meio de uma leitura cognitivocomportamental, possibilidades de intervenção da Psicologia frente aos impactos negativos dessa associação.

O estudo foi desenvolvido pelo método de estudo de caso, que, de acordo com Boente e Braga (2004), busca descrever e analisar aspectos específicos de um fenômeno. Pasqualotti (n.d.) assevera que o pesquisador, na chamada Era da Informação (grifo nosso), esbarra com o excesso de dados disponíveis, o que dificulta seu trabalho na medida em que necessita avaliar quais serão elegíveis para seu interesse. Sendo assim, a ética deve fazer-se presente desde a escolha do método e da amostra a compor o estudo. Especificamente para pesquisas que envolvem seres humanos, a legislação brasileira, por meio da Resolução n. 466, de 12 de dezembro de 2012, postula que os riscos e benefícios devem ser ponderados de 
forma que sobressaiam os últimos (Resolução n. 466, 2012). Diante disso, com base na legitimidade da poesia e da arte como ferramentas para desvendar questões da existência individual e coletiva (MINAYO, 200I), optou-se pela inovação de eleger como amostra um texto fictício: a letra da canção Um Homem Também Chora, de Gonzaguinha (1983):

Um homem também chora/Menina morena/Também deseja colo/Palavras amenas

Precisa de carinho/Precisa de ternura/Precisa de um abraço/Da própria candura

Guerreiros são pessoas/São fortes, são frágeis/Guerreiros são meninos/No fundo do peito

Precisam de um descanso/Precisam de um remanso/Precisam de um sono/Que os tornem refeitos

É triste ver meu homem/Guerreiro menino/Com a barra do seu tempo/Por sobre seus ombros

Eu vejo que ele berra/Eu vejo que ele sangra/A dor que tem no peito/Pois ama $\mathrm{e}$ ama

Um homem se humilha/Se castram seus sonhos/Seu sonho é sua vida/E vida é trabalho

E sem o seu trabalho/O homem não tem honra/E sem a sua honra/Se morre, se mata

Não dá pra ser feliz/Não dá pra ser feliz (GONZAGUINHA, 1983)

Uma vez selecionada, a amostra foi submetida aos procedimentos de contextualização e análise, visando a atender aos seguintes objetivos específicos:

I. Apresentar recortes da relação homem-trabalho no Brasil em três momentos da história contemporânea, a saber: década de 1980 (final da Ditadura Militar), virada do século (enfatizando a globalização e o avanço tecnológico) e a partir de 2020 aos dias atuais (no contexto da pandemia de Covid-r9).

2. Levantar as possíveis contribuições da Terapia Cognitivo-Comportamental, para o enfrentamento de impactos negativos da falta de trabalho, cotejando os fundamentos de Ellis e de Beck, visando a prevenir a instalação de sintomas frente a essa contingência.

Em suma, planeja-se buscar na TCC soluções para conflitos da ordem da relação homem-trabalho, gerados a partir do evento adverso da ausência do trabalho.

Além de contribuir para a compreensão do sofrimento do indivíduo, os resultados dessa pesquisa são relevantes para o desenvolvimento da Psicologia do Trabalho, já que, 
conforme postula Dejours (2015), a problemática ora estudada encontra-se na raiz de muitos casos de adoecimento físico e mental do ser-humano.

\section{RELAÇÃO HOMEM-TRABALHO}

A palavra trabalho tem origem no vocábulo do latim vulgar tripalium, nome de um antigo instrumento de tortura feito de três estacas de madeira pontiagudas. Portanto, trabalhar (tripaliari) aproxima-se semanticamente de ser torturado, tal como eram castigados escravos e pobres, em tempos remotos na região europeia, por não terem condições de arcar com o pagamento de impostos. (DICIONÁRIO ETIMOLÓGICO, 2008-202I)

Araújo e Sachuk (2007) atentam para a tendência da cultura ocidental de considerar o trabalho como dever/obrigação perante Deus ou a humanidade, ou ainda como forma de dominação do ser humano em relação à natureza.

Ao longo da História, houve mudanças relevantes na relação homem-trabalho, dentre as quais destacam-se as três revoluções (ou três ondas) assim elencadas por Toffler (1980):

- Primeira: há cerca de dez mil anos, marcada pela prática da agricultura que permitiu ao homem passar de nômade a sedentário;

- Segunda: a mudança de civilização agrícola para basicamente industrial, há mais de 300 anos;

- Terceira: a sociedade da informação, iniciada na última década do século XX, e que permanece nos tempos hodiernos.

Toffler (1980) postula que a terceira onda vem criando um novo modo de vida e de trabalho. Se, em tempos anteriores, valorizava-se o trabalho braçal e mecânico, hoje, a maior força está no conhecimento. Segundo o autor, o trabalhador passa a ser mais valorizado por sua criatividade do que por sua força física e capacidade de seguir ordens sem questionar.

Já em 1930, Vigotski anunciava que as transformações nas relações de trabalho refletiriam na formação da personalidade humana. Para o estudioso, sendo o homem ser social, a estrutura do meio onde vive influenciará diretamente na sua constituição psíquica. Bebendo nas teorias de Engels e Marx, Vigotski vê na divisão do trabalho e, 
consequentemente, das classes sociais, o cerne para a secção do caráter humano em distintas personalidades. (VIGOTSKI, I930)

A relação homem-trabalho, guardadas as devidas proporções, se dá, em geral, às voltas com o adoecimento físico e/ou psíquico. Esse tema é fruto de estudos de Christophe Dejours (2015), que discute as relações entre a organização do trabalho e a saúde dos trabalhadores, abordando questões como a luta pela sobrevivência, o medo do desemprego, entre outras.

No Brasil contemporâneo, a relação homem-trabalho é fruto de um passado histórico, ainda recente, marcado pela exploração da mão-de-obra escrava até as últimas décadas do século XIX e, posteriormente, substituída pela força de trabalho de imigrantes. Assim, a economia do país na primeira década do século XX estaria pautada na subsistência. Entre os anos de 1930 e 1980, houve forte modernização e industrialização na sociedade brasileira, levando a um movimento de migração do campo para as cidades. No entanto, essa urbanização não foi suficiente para absorver a mão-de-obra excedente, nem tampouco o faria a revolução tecnológica da virada do século. (DELGADO, 2005)

$\mathrm{Na}$ década de 1980, o Brasil também foi palco de uma reabertura política, marcada pelo fim da ditadura militar, que durou de 1964 a 1985 . No tocante ao trabalho, a virada ocorreu com a promulgação da Constituição de 1988. Embora já houvesse no país, desde 1943, a Consolidação das Leis do Trabalho - CLT -, o tratamento dispensado a esta instituição era o de dever. Só em 1988 é que se lhe atribuiu o status de direito. (SENA, 2019)

$\mathrm{Na}$ Constituição anterior, de 1967, o trabalho era citado, não em pé de igualdade, mas como condição para dignidade humana. O que significa dizer que, para ter direito à dignidade, o ser humano tem o dever de trabalhar (BRASIL, 1969). Já, na chamada Constituição Cidadã de 1988, passa-se a considerar valores sociais do trabalho, bem como os da livre iniciativa, como um dos princípios fundamentais do Estado Democrático de Direito. O trabalho equipara-se, portanto, à soberania, à cidadania, à dignidade da pessoa humana e ao pluralismo político (BRASIL, 1988).

O fato é que, quer seja como dever ou como direito, o trabalho continuava sendo ponto de dificuldade na vida do brasileiro, pois, de acordo com Delgado (2005), nesse período - décadas de 80 e 90 -, a economia do país sofria uma estagnação. E a massa de 
mão-de-obra, que migrara do campo, dividiu-se, na cidade, entre assalariados e trabalhadores informais, todos tentando driblar o crescente desemprego.

O século XXI trouxe consigo a ascensão digital e da informação. Conforme observam Kohn e Moraes (2007), a riqueza de um país se mede por sua capacidade de acesso tecnológico. Além disso, a informação permite, e até incentiva, a comunicação a distância, unindo países e culturas diferentes - a chamada globalização.

Mattos (2004) pondera que os países menos desenvolvidos, que têm menor poder de decisões financeiras no mundo globalizado, dentre os quais encontra-se o Brasil, buscam maneiras de equiparar-se aos mercados mais desenvolvidos. Nesse intuito, submetem-se a ideias de desregulamentação e flexibilização de leis trabalhistas, que acabam por refletir na precarização do trabalho.

Milton Santos (20or) afirma que a idealizada globalização, que uniria a humanidade, na prática, trouxe consumismo e competitividade, matando a noção de solidariedade. Para o estudioso, o homem regrediu ao estágio primitivo do individualismo, tendo reduzidas a quase nada as noções de moralidade. Além disso, a globalização atualizou a exclusão, produzindo novas dívidas sociais.

Quando o modelo econômico e produtivo se baseia na informação, os que não têm acesso ao conhecimento tornam-se excluídos digitais. Consequentemente, cresce o contingente de desempregados, subempregados e trabalhadores informais. (PEREIRA, 2003)

\section{O CONTEXTO PANDÊMICO E OS IMPACTOS DA COVID-ı9 AO TRABALHO}

A terceira década do terceiro milênio inicia-se num contexto pandêmico. Um vírus identificado em dezembro de 2019, na China, deu origem à Covid-ı, uma doença infectocontagiosa, que levaria a Organização Mundial de Saúde a recomendar, entre as principais medidas de contenção do contágio, o isolamento social (WHO, s/d).

De acordo com Pires (2020), em âmbito mundial, há confluência de duas crises: uma sanitária e outra econômica. O autor postula que a Covid-ıg não é causa única da crise na economia global, que, pautada sobretudo no sistema capitalista, já estava dando sinais de deflagração. Entretanto, reconhece na pandemia um gatilho para que a queda na produção mundial, já desenhada, se instaurasse. A paralisação total ou parcial em 
diferentes países, em razão da necessidade de isolamento social, acarreta queda do PIB global e, consequente retorno de milhões de pessoas à condição de pobreza extrema. Como se pode esperar, os impactos de ambas as crises - sanitária e econômica - são mais severos para os trabalhadores, sobretudo nos países periféricos.

No Brasil, os reflexos da pandemia se notam no alto índice de desocupação - 14,7\% no primeiro trimestre de 2021, o maior já levantado desde o início da série de coleta de dados, em 2012 (IBGE, 2021b). O sistema de divisão do mercado de trabalho no Brasil tem mantido subutilizados quase $1 / 3$ de sua população total, incluindo nessa categoria pessoas desocupadas, pessoas ocupadas com carga horária reduzida e pessoas desalentadas, ou seja, aquelas que desistiram de procurar trabalho por conhecerem dificuldades em encontrar (IBGE, 202ıa). Assim, a taxa de subutilização de força de trabalho no Brasil, medida entre janeiro e março de 2021, chega a 29,7\% (IBGE, 2021a).

Para Antunes e Alves (2004), as mutações no mundo do trabalho, gerando precarização das condições trabalhistas, bem como aumento das massas desempregadas, contribuem para o adoecimento mental dos indivíduos, levando a reações diversas, tais como isolamento social, apatia e mesmo violência e agressão. Dejours (2015) acrescenta que, dada a necessidade de sobrevivência, o homem vai assumindo um comportamento voltado à produção, anulando o que seria seu comportamento livre. Uma anulação que afeta muda e invisivelmente a saúde mental e física do trabalhador.

\section{A TERAPIA COGNITIVO-COMPORTAMENTAL - TCC}

A Terapia Cognitivo-Comportamental-TCC - é, de acordo com Wenzel (2018), um tipo de psicoterapia semiestruturada, de duração limitada, em que terapeuta e cliente trabalham ativa e colaborativamente sobre padrões cognitivos e comportamentais que estejam causando sofrimento na vida do cliente.

Comumente se faz uso da nomenclatura Terapia Cognitiva - TC - como sinônimo de TCC, o que não está completamente correto. Enquanto esta se refere a uma combinação de abordagem cognitiva com procedimentos comportamentais, aquela descreve psicoterapias baseadas no modelo cognitivo. No entanto, ambas consideram a influência direta dos pensamentos, crenças e percepções no comportamento humano e, portanto, tratam a cognição como mediadora do comportamento. (BECK, 2007) 
A evolução dessas teorias, desde a origem no século $\mathrm{XX}$ até os dias atuais, levou os estudiosos a classificá-las em três ondas. Antes de representar uma separação entre correntes distintas, esse movimento evolutivo é marcado por um casamento entre os conhecimentos. (BARBOSA; TERROSO; ARGIMON, 20I4)

A chamada primeira onda da Terapia Cognitivo-Comportamental focava, fundamentalmente, no aspecto comportamental, tendo como modelo a teoria do condicionamento desenvolvida por Ivan Pavlov. Inclui-se nessa classe o Behaviorismo Radical de Burrhus Frederic Skinner (BARBOSA; TERROSO; ARGIMON, 2014).

Com o avanço da revolução cognitiva, as terapias passaram a considerar as crenças do indivíduo, incorporando técnicas cognitivas às comportamentais. É o que se pode observar na prática de Ellis e Beck, entre outros, cujos estudos constituem a segunda onda e compõem a base das Terapias Cognitivo-Comportamentais (TCC). (WENZEL, 2018)

A terceira onda, por sua vez, veio complementar a TCC, abrangendo diversos modelos de intervenção, marcadas pela sensibilidade ao contexto. Assim, para as novas abordagens, o homem não é visto como um ser universal, mas, como resultado de transformações sociais. Dentro dessa concepção, as teorias e práticas desenvolvidas a partir das décadas de 1980 e 1990 passaram a alcançar resultados significativos em quadros de transtornos de personalidade, a partir da utilização de ferramentas complementares à clínica, como é o caso das práticas meditacionais. Assim, buscando a flexibilidade psicológica, aplicam-se conceitos como mindfulness, aceitação, compromisso, unindo conhecimentos das três ondas da TCC. (BARBOSA; TERROSO; ARGIMON, 2014)

Guardadas as devidas proporções, as abordagens do escopo da TCC unem-se pelo princípio fundamental de que a percepção do indivíduo sobre a realidade influenciará seus comportamentos e sentimentos. Essa atenção para com a subjetividade do indivíduo revela, na constituição da TCC, contribuições da psicologia humanista de abordagem fenomenológica. Não obstante, a estruturação dos procedimentos aplicados na Terapia Cognitivo-Comportamental assemelha-se à Terapia Comportamental, embora, a exemplo da Psicanálise, seu interesse esteja mais focado nos processos intrapsíquicos do que no comportamento observável. Considerando-se que a percepção e o processamento dos eventos pelo indivíduo podem alterar a realidade, a TCC busca corrigir e reestruturar os pensamentos distorcidos. Muitos destes surgem de maneira abrupta, fugindo ao fluxo 
reflexivo. Esses intrusos são os pensamentos automáticos, dificilmente detectados por pessoas que não estejam treinadas para isso. (KNAPP; BECK, 2008).

Cumpre observar que há distinção pensamentos e sentimentos. Pensamentos podem criar sentimentos, que, por sua vez, são experiências internas de emoções. Emoções são, portanto, a parte visível, expressiva dos sentimentos. (LEAHY, 2006).

A TCC, ao favorecer a flexibilidade cognitiva, visa a promover melhora no estado de humor do indivíduo, por meio de reestruturação de pensamentos disfuncionais, que devem, aos poucos, ser substituídos por pensamentos mais adaptativos. (BECK, 2007).

$\mathrm{Na}$ raiz desses pensamentos automáticos estão as crenças nucleares ou centrais, que são conteúdos internos, constituídos por informações e experiências pessoais e identificação com pessoas significativas, que, armazenadas ao longo do tempo, tornam-se enraizadas, de modo a influenciar os pensamentos e comportamentos do indivíduo. Esses conteúdos formam estruturas profundas, denominadas esquemas. (KNAPP; BECK, 2008).

As crenças nucleares são incondicionais e podem refletir na visão do indivíduo sobre si mesmo, sobre o mundo e sobre o futuro, formando a tríade cognitiva. Tais crenças podem-se agrupar sob três formas: desamparo, desamor e desvalor. Além dos pensamentos automáticos - PA - e das crenças nucleares, a Terapia Cognitiva postula um nível de cognição intermediário: são as crenças subjacentes, formadas por regras e pressupostos condicionais (KNAPP, 2004b).

Segundo Knapp e Beck (2008), em todos os níveis cognitivos pode haver distorções. A ativação de determinados esquemas disfuncionais pode causar prejuízo na capacidade do sujeito de avaliar objetivamente os eventos. São exemplos de distorções cognitivas:

I. Catastrofização - Pensar que o pior de uma situação irá acontecer, sem levar em consideração a possibilidade de outros desfechos. Acreditar que o que aconteceu ou irá acontecer será terrível e insuportável. Exemplos: "Perder o emprego será o fim da minha carreira". "Eu não suportarei a separação da minha mulher". "Se eu perder o controle será meu fim".

2. Raciocínio emocional (emocionalização) - Presumir que sentimentos são fatos. Pensar que algo é verdadeiro porque tem uma emoção (na verdade, um pensamento) muito forte a respeito. Deixar os sentimentos guiarem a interpretação da realidade. Presumir que as reações emocionais necessariamente refletem a situação verdadeira. Exemplos: "Eu sinto que minha mulher não gosta mais de mim". "Eu sinto que meus colegas estão rindo às minhas costas". "Sinto-me desesperado, portanto, a situação deve ser desesperadora".

3. Polarização (pensamento tudo-ou-nada, dicotômico) - Ver a situação em duas categorias apenas, mutuamente exclusivas, ao invés de um continuum. 
Perceber eventos ou pessoas em termos absolutos. Exemplos: "Deu tudo errado na festa". "Devo sempre tirar a nota máxima, ou serei um fracasso". "Ou algo é perfeito, ou não vale a pena". "Tudo foi uma perda de tempo total".

4. Abstração seletiva (visão em túnel, filtro mental, filtro negativo) - Um aspecto de uma situação é o foco da atenção, enquanto outros aspectos relevantes da situação são ignorados. Uma parte negativa (ou mesmo neutra) de toda uma situação é realçada, e todo restante positivo não é recebido. Exemplos: "Veja todas as pessoas que não gostam de mim". "A avaliação do meu chefe foi ruim" [focando apenas um comentário negativo e negligenciando todos os comentários positivos].

5. Leitura mental - Presumir, sem evidências, que sabe o que os outros estão pensando, desconsiderando outras hipóteses possíveis. Exemplos: "Ela não está gostando da minha conversa". "Ele está me achando inoportuno". "Ele não gostou do meu projeto".

6. Rotulação - Colocar um rótulo global, rígido em si mesmo, numa pessoa, ou situação, ao invés de rotular a situação ou comportamento específico. Exemplos: "Sou incompetente". "Ele é uma pessoa má". "Ela é burra".

7. Minimização e maximização - Características e experiências positivas em si mesmo, no outro ou nas situações são minimizadas enquanto o negativo é magnificado. Exemplos: "Eu tenho um ótimo emprego, mas todo mundo tem". "Obter notas boas não quer dizer que eu sou inteligente, os outros obtêm notas melhores do que $e u$ ".

8. Imperativos ("Deveria" e "Tenho-que") - Interpretar eventos em termos de como as coisas deveriam ser, ao invés de simplesmente focar em como as coisas são. Afirmações absolutistas na tentativa de prover motivação ou modificar um comportamento. Demandas feitas a si mesmo, aos outros e ao mundo para evitar as consequências do não cumprimento destas demandas. Exemplos: "Eu tenho que ter controle sobre todas as coisas". "Eu devo ser perfeito em tudo que faço". "Eu não deveria ficar incomodado com minha esposa". (KNAPP; BECK, 2008)

Enquanto Beck nomeia disfunções cognitivas, Ellis traz o conceito de crenças irracionais, que, de acordo com DiGiuseppe et al. (2014), seriam "expressões cognitivas de uma falta de vontade para aceitar um resultado não desejado da realidade vinculado ao esforço para conquistar algo positivo ou bloquear algo negativo". Portanto, o elemento irracional compreende aquilo que impede a pessoa de atingir seus objetivos e metas.

Dentre os princípios da terapia proposta por Albert Ellis está o de que o determinante mais importante das emoções humanas são as cognições. Consequentemente, na base de toda perturbação emocional encontra-se uma cognição irracional. (DIGIUSEPPE et al., 2014).

Delgado (2019) refere que a TREC atual condensa as crenças irracionais em:

I. Demandas - são consideradas irracionais básicas e expressam expectativas não realistas, geralmente por meio do uso de termos como "devo", "tenho que", "preciso", por pessoas que convertem seus fortes desejos em exigências. Exemplos: "Preciso da aprovação e do carinho dos outros". "Ele/ela deveria se 
comportar de forma considerada honesta, justa". "As coisas deveriam ser de outra maneira".

2. Catastrofização - Ressaltar os aspectos negativos de um acontecimento adverso, enxergando a situação não somente como ruim, mas como terrível considerando, inclusive, que nada poderia ser pior. Exemplo: "É/seria terrível, horrível, o pior do mundo se acontecesse/que tenha acontecido...".

3. Intolerância à frustração - Representa a não vontade de manter-se em uma situação difícil ou de tolerar o grau de frustração necessária que poderia permitir à pessoa conquistar seus objetivos. Exemplos: "Não suporto isso". "Não resisto". "É muito difícil, e não vou conseguir".

4. Avaliação Global - Pensamentos que implicam em uma qualificação global das situações ou dar uma valoração absoluta às pessoas em função de suas características, rendimentos, comportamentos, assim como com a aceitação ou rejeição dos outros. Exemplos: "Sou um idiota". "Ele é um estúpido, um débil ou incompetente". "O mundo é mau".

De acordo com DiGiuseppe et al (2014), Ellis aposta na possibilidade de mudança das crenças e assevera que não se trata de tarefa simples. A partir de esforço e persistência, a pessoa pode construir posturas diferentes. Em consonância com esse princípio, Delgado (2019) aponta que para cada tipo de crença irracional contrapõe-se um tipo de crença racional, que contribui para que a pessoa alcance seus objetivos e metas. São crenças racionais:

I. Desejos, gostos ou preferências - são crenças racionais consideradas básicas para a saúde psicológica das pessoas. Consistem em reconhecer que nem tudo que se deseja é possível, nem tudo o que é indesejável se pode evitar. É comum expressar-se por "eu gostaria", "seria bom que". Exemplos: "Seria bom ser aprovado na faculdade".

2. Avaliação moderada do mal - refere-se a uma visão mais realista e objetiva de acontecimentos adversos, considerando que são ruins, desagradáveis, mas, não necessariamente terríveis ou o pior do mundo. Exemplos: "É/seria muito ruim, mas não terrível nem o pior... que tenha acontecido/aconteça...”.

3. Tolerância à frustração - refere-se à compreensão de que os acontecimentos podem resultar em frustrações, dificuldades ou incômodos, mas que a pessoa conta com recursos para enfrentá-los. Esse tipo de pensamento representa a vontade da pessoa de se manter em uma situação difícil e/ou tolerar o grau de frustração necessário para que atinja seus objetivos. Exemplo: "Não gosto, é difícil para mim, inconveniente, mas posso lidar com isso".

4. Aceitação incondicional - pensamentos que demarcam avaliação das pessoas sobre suas características, comportamentos e resultados. Trata-se da compreensão de que todas as pessoas, indistintamente, são valiosas e que podem falhar. Exemplos: "Eu tive um mau comportamento/cometi um erro/tive uma rejeição... isso não me torna um idiota". "Meu comportamento/resultado não define meu valor como pessoa nem dos demais". (DELGADO, 2019)

Knapp e Beck (2008) alertam para a intrínseca ligação entre afeto e cognição, ressaltando que a vulnerabilidade de um resulta em perigo de instabilidade no outro. 
Judith Beck (2007) assevera que é comum o sujeito confundir pensamentos automáticos com emoções. Assim, um dos trabalhos do terapeuta, para a TCC de Aaron Beck, será clarificar as diferenças entre ambos e, a partir daí, favorecer a identificação e a desconstrução dos pensamentos disfuncionais, para que o indivíduo consiga, aos poucos, substituir emoções negativas por outras positivas.

Diferentemente de outras orientações cognitivo-comportamentais, a TREC aborda as emoções não pela classificação em positiva ou negativa, mas por seu aspecto de saudável ou não saudável, observando que uma emoção negativa pode ser saudável se for proporcional à experiência adversa que a pessoa esteja vivendo. Ao terapeuta, portanto, caberá trabalhar sobre as emoções não saudáveis, procurando fazer com que a pessoa aprenda roteiros emocionais adaptados/funcionais, para que escolha sentir emoções saudáveis ao invés de emoções perturbadas. (DELGADO, 2019)

Pela TREC é possível considerar a seguinte classificação das emoções:

Quadro I - Classificação das emoções pela TREC

\begin{tabular}{|l|l|}
\hline Saudáveis e funcionais & Não saudáveis e disfuncionais \\
\hline Preocupação & Ansiedade \\
\hline Tristeza & Depressão \\
\hline Irritação & Ira, raiva \\
\hline Arrependimento, remorso & Culpa \\
\hline Desconforto, decepção & Vergonha \\
\hline Pena & Mágoa \\
\hline
\end{tabular}

Fonte: Adaptado de DIGIUSEPPE; DOYLE; DRYDEN; BACK (2014).

De modo geral, as terapias de orientação cognitivo-comportamental preconizam trabalhar os padrões cognitivos e comportamentais que venham a causar sofrimento na vida do indivíduo (WENZEL, 2018). Considerando-se a influência que o trabalho pode ter na saúde física e psíquica do ser humano, conforme postula Dejours (2015), torna-se possível buscar, tanto na TREC quanto na TCC, ferramentas para enfrentamento da adversidade da falta de trabalho, evitando que sintomas patológicos venham a se instalar diante da situação negativa consumada. Nessa direção norteia-se o presente estudo, 
justificado pela necessidade da manutenção da saúde, enquanto bem-estar biopsicossocial e espiritual, mesmo diante dos sofrimentos causados pelo desemprego, que tem impactado grande parte da sociedade brasileira contemporânea.

\section{RESULTADOS E DISCUSSÃO}

Embora não seja de interesse desta pesquisa aprofundar-se em teoria literária, a leitura do texto permite inferir a presença de um narrador onisciente, que não apenas observa, mas conhece os pensamentos e sentimentos das personagens observadas (BARTHES et al, 20II; TAVARES, 1966; TODOROV, 2008). É esse narrador quem identifica o sujeito do caso: um homem, a quem qualifica como guerreiro e menino, modo pelo qual passará a ser referido nesta análise.

De modo geral, as terapias relacionadas no escopo da TCC consideram a existência de uma tríplice contingência, que envolve uma situação antecedente, eliciadora de determinada resposta que, por sua vez, gerará consequências de ordem emocional, comportamental e/ou cognitiva no sujeito (WENZEL, 20r8, BARBOSA; TERROSO; ARGIMON, 2014, KNAPP, 2004a). Assim, pode-se depreender do caso apresentado a situação de falta de trabalho como evento ativador da sequência contingencial. Aplicandose a teoria de Aaron Beck (WENZEL, 2018), a tríplice contingência se apresentaria conforme abaixo:

\begin{tabular}{|l|l|l|}
\hline Situação Antecedente & Resposta & $\begin{array}{l}\text { Consequência } \\
\text { (emocional, comportamental ou } \\
\text { cognitiva) }\end{array}$ \\
\hline falta de trabalho & $\begin{array}{l}\text { Sou incapaz. } \\
\text { serrangrar chorar (emocional, cognitiva) } \\
\text { sentir-se infeliz (emocional) } \\
\text { (desejar) morrer (emocional, cognitiva) }\end{array}$ \\
\hline
\end{tabular}

Wenzel (2018) ressalta a interferência da cognição sobre essa relação, já que não é a situação em si que elicia a resposta, mas, sim, as ideias ou julgamentos que se lançam sobre ela. Nesse sentido, há que se considerar a relevância do contexto para o estabelecimento da tríplice contingência (BARBOSA; TERROSO; ARGIMON, 2014). Assim, recuperando-se a época histórica em que foi escrito o texto Um homem também chora - 1983 - encontra-se um 
país - Brasil - às voltas com a ditadura militar. Nesse cenário, a visão de homem e de mundo tende a ser influenciada pelo clima de obediência, em que o valor do cidadão se pauta sobremaneira por sua inserção no mercado de trabalho (SENA, 2019). A marca contextual revela-se literalmente nos versos "Com a barra do seu tempo/Por sobre seus ombros" (GONZAGUINHA, 1983). O trabalho, na visão do Guerreiro Menino, equiparase à própria vida, e a falta dele seria, portanto, equivalente à perda da honra. Consequentemente, o indivíduo sente-se infeliz, podendo ser levado à morte. Essa análise possibilita enquadrar a tríplice contingência no modelo $\mathrm{ABC}$ de Ellis:

\begin{tabular}{|l|l|l|}
\hline $\begin{array}{l}\text { A } \\
\text { (Evento Ativador) }\end{array}$ & $\begin{array}{l}\text { B } \\
\text { (Beliefs: Crenças) }\end{array}$ & $\begin{array}{l}\text { C } \\
\text { (Consequências) }\end{array}$ \\
\hline $\begin{array}{l}\text { Situação: } \\
\text { falta de trabalho } \\
\text { Inferência: } \\
\text { perda do valor } \\
\text { humano }\end{array}$ & incapacidade & $\begin{array}{l}\text { berrar (chorar) } \\
\text { sangrar } \\
\text { sentir-se infeliz } \\
\text { (desejar) morrer }\end{array}$ \\
\hline
\end{tabular}

Deslocando-se o caso para outro período na linha do tempo, a virada do milênio, o evento falta de emprego passa a ter um novo elemento contextual: a globalização, alavancada pelos avanços da tecnologia da informação (KOHN; MORAES, 2007). Se, por um lado, esse desenvolvimento passa a ser a medida da riqueza de um país, por outro, cria uma nova modalidade de exclusão, a exclusão digital, que, à medida que atinge a parcela mais pobre da população, gera uma nova dívida social ao Brasil (SANTOS, 200I). Isso ocorre num momento histórico em que o trabalho já é visto como um direito do cidadão, equiparado, pela Constituição de 1988, à dignidade da pessoa humana (BRASIL, I988; SENA, 2019).

Nos anos 200o, perder o emprego representaria, para o Guerreiro Menino, ser cerceado de um direito fundamental, o que lhe poderia eliciar sentimento de revolta. Por outro lado, o fato de ser excluído por falta de conhecimento específico para a Era Digital, pode ativar crenças de incapacidade, de inutilidade, de inadequação, de incompetência. Beck identificaria: 


\begin{tabular}{|l|l|l|}
\hline Situação Antecedente & Resposta & $\begin{array}{l}\text { Consequência } \\
\text { (emocional, comportamental ou } \\
\text { cognitiva) }\end{array}$ \\
\hline falta de trabalho & Fui injustiçado. & $\begin{array}{l}\text { berrar, chorar (comportamental) } \\
\text { sangrar (emocional, cognitiva) }\end{array}$ \\
Sou incompetente. & $\begin{array}{l}\text { sentir-se infeliz (emocional) } \\
\text { (desejar) morrer (emocional, } \\
\text { cognitiva) }\end{array}$ \\
\hline
\end{tabular}

Pela visão de Ellis:

\begin{tabular}{|c|c|c|}
\hline $\begin{array}{l}\text { A } \\
\text { (Evento Ativador) }\end{array}$ & $\begin{array}{l}\text { B } \\
\text { (Beliefs: Crenças) }\end{array}$ & $\begin{array}{l}\text { C } \\
\text { (Consequências) }\end{array}$ \\
\hline $\begin{array}{l}\text { Situação: } \\
\text { falta de trabalho } \\
\text { Inferência: } \\
\text { exclusão social }\end{array}$ & $\begin{array}{l}\text { injustiça } \\
\text { incompetência } \\
\text { inutilidade }\end{array}$ & $\begin{array}{l}\text { revolta } \\
\text { violência } \\
\text { (desejar) matar } \\
\text { sentir-se envergonhado } \\
\text { (desejar) morrer }\end{array}$ \\
\hline
\end{tabular}

Uma terceira possibilidade seria analisar o caso no contexto atual, dos anos 2020/2021, marcado pela pandemia da Covid-19. A crise sanitária, que se deflagrou em todo o mundo, fez agravar a crise econômica brasileira, culminando com o retorno de milhões de pessoas à condição de pobreza extrema (PIRES, 2020).

As restrições à circulação geraram mudanças nas relações de trabalho: a modalidade de trabalho remoto, também conhecida como home-office ou teletrabalho, que já vinha ganhando campo devido ao avanço da Era da Informação, instalou-se definitivamente (GÓES; MARTINS; NASCIMENTO, 2020). No entanto, os excluídos digitais passaram a engrossar ainda mais a massa de desempregados (BARBOSA; HOLANDA, 2020).

Relacionando-se essa realidade com o caso em análise, o contexto pandêmico seria um reforçador das dificuldades, vistas como peso nos ombros do Guerreiro Menino.

Tolfo e Piccinini (2007) postulam que o trabalho é dotado de significado e de sentido. Enquanto aquele resulta de um construto coletivo, histórico e social, este 
relaciona-se com a experiência individual. Uma vida plena de sentido supõe que haja também sentido no trabalho (ANTUNES, 200o). Os impactos do trabalho e, por conseguinte, da ausência deste, tendem a ser diferentes para diferentes indivíduos, pois refletem variáveis subjetivas: a) o significado atribuído ao trabalho; b) a centralidade do trabalho na vida do indivíduo; c) a ética individual; d) o motivo de se trabalhar (MOW, I987; TOLFO; PICCININI, 2007).

A descrição do caso ora em estudo remete à inferência de que o trabalho tem centralidade absoluta na existência do sujeito, conforme se atesta no verso "E vida é trabalho". Trabalhar, para ele, é tanto reflexo de seus valores éticos, uma vez que representa a honra, como fonte de prazer, já que representa seu sonho: "Seu sonho é sua vida".

De modo geral, as alterações no mundo do trabalho e a necessidade de sobrevivência vão interferindo no comportamento do trabalhador, que passa a anular sua liberdade em prol da cultura de produção (DEJOURS, 2015). A instalação do teletrabalho é um exemplo dessa anulação da liberdade, uma vez que invade o espaço residencial, antes reservado ao descanso e ao convívio familiar (GÓES; MARTINS; NASCIMENTO, 2020).

Antunes e Alves (2004) observam que a precarização das condições trabalhistas expõe o indivíduo ao adoecimento físico e mental, de tal forma que pode levá-lo a reações diversas: desde o isolamento social e a apatia, até atos de violência e agressão. Não se trata aqui apenas do isolamento necessário para conter o avanço da pandemia, mas o isolamento que, acompanhado de outros sintomas, pode sinalizar depressão ou outras patologias (APA, 2014). Quanto à violência, a Organização das Nações Unidas (2020) alerta para o risco de aumento nas agressões em ambiente doméstico, facilitado pelo maior convívio entre vítima e agressor, em função do isolamento social.

No caso em estudo, a instabilidade emocional pode-se refletir no Guerreiro Menino em forma de insegurança, fragilidade e vulnerabilidade, demonstradas em todo o texto, sobretudo na primeira estrofe, a exemplo dos versos: "Também deseja colo" e "Precisa de carinho" (GONZAGUINHA, 1983). Aplicando-se o modelo de Aaron Beck, pode-se supor: 


\begin{tabular}{|l|l|l|}
\hline Situação Antecedente & Resposta & $\begin{array}{l}\text { Consequência } \\
\text { (emocional, comportamental ou } \\
\text { cognitiva) }\end{array}$ \\
\hline falta de trabalho & $\begin{array}{l}\text { Estou desamparado. } \\
\text { Sou frágil. }\end{array}$ & $\begin{array}{l}\text { solidão } \\
\text { carência } \\
\text { querer colo } \\
\text { descansar } \\
\text { desânimo } \\
\text { paralisar } \\
\text { astou cansado. } \\
\text { A vida é difícil. } \\
\text { Não posso fazer nada. } \\
\text { Ninguém me ajuda. } \\
\text { agressividade } \\
\text { (desejar) matar } \\
\text { desesperança } \\
\text { (desejar) morrer }\end{array}$ \\
& Não tenho saída. & \\
\hline
\end{tabular}

No modelo de Ellis (WENZEL, 20I8), a contingência poderia ser apresentada como:

\begin{tabular}{|c|c|c|}
\hline $\begin{array}{l}\text { A } \\
\text { (Evento Ativador) }\end{array}$ & $\begin{array}{l}\text { B } \\
\text { (Beliefs: Crenças) }\end{array}$ & $\begin{array}{l}\text { C } \\
\text { (Consequências) }\end{array}$ \\
\hline $\begin{array}{l}\text { Situação: } \\
\text { falta de trabalho } \\
\text { Inferência: } \\
\text { perda do sentido da vida e } \\
\text { do meio de sobrevivência }\end{array}$ & $\begin{array}{l}\text { desamparo } \\
\text { fragilidade } \\
\text { cansaço } \\
\text { dificuldade (da vida) } \\
\text { impotência }\end{array}$ & $\begin{array}{l}\text { solidão } \\
\text { carência } \\
\text { querer colo } \\
\text { descansar } \\
\text { desânimo } \\
\text { paralisar } \\
\text { raiva } \\
\text { berrar (gritar) } \\
\text { agressividade } \\
\text { (desejar) matar } \\
\text { desesperança } \\
\text { (desejar) morrer }\end{array}$ \\
\hline
\end{tabular}


Constatados os impactos negativos da falta de trabalho sobre o indivíduo, passa-se a buscar ferramentas de enfrentamento que auxiliem na prevenção da instalação de sintomas patologizantes. Nesse sentido, é importante que distorções cognitivas sejam identificadas e, na medida do possível, alteradas. Para corrigir pensamentos distorcidos, é necessário, antes, que se diferenciem fatos, pensamentos e sentimentos, admitindo-se o pressuposto de que pensamentos - que podem ser hipóteses, descrições, perspectivas ou mesmo adivinhações - geram sentimentos (LEAHY, 2006). No modelo de Beck, a situação antecedente representaria o fato; a resposta, os pensamentos; já os sentimentos estariam entre as consequências, dividindo espaço com comportamentos e reações físicas (KNAPP, 2004a; WENZEL, 2018).

O trabalho de Aaron Beck exige, em primeiro lugar, a identificação do pensamento, o que nem sempre é tarefa fácil. Muitas vezes, é necessário, antes, identificar o afeto. Judith Beck (2007) assevera que, partindo de um sentimento, se deve buscar a resposta ao principal questionamento da TCC: “O que estava passando pela minha mente?”. Ao perceber quais pensamentos estão por trás de determinados sentimentos, o indivíduo começa a educar-se cognitivamente para tentar evitar os pensamentos negativos (BECK, 2007).

Diversas técnicas podem ser utilizadas para auxiliar o sujeito a chegar à resposta: uma delas é a descoberta guiada. Por meio de questionamento socrático, vai-se conduzindo o indivíduo a avaliar a validade e as consequências de suas cognições. (BECK, 2007; KNAPP, 2004a; LEAHY, 2006). Uma possível aplicação do questionamento socrático ao caso seria:

Situação: perda do emprego.

Questão: Como se sente hoje?

Possível resposta: Triste.

Questão: O que passa por sua cabeça que o deixa triste?

Possível resposta: Estou desempregado.

Questão: E o que isso significa para você?

Possível resposta: Que sou incompetente.

Questão: Quais as evidências de que seu pensamento é verdadeiro?

Possível resposta: Fui demitido. 
Questão: Quais as evidências de que seu pensamento não é verdadeiro?

Possível resposta: Trabalhei por muitos anos nessa empresa.

Questão: E o que isso significa?

Possível resposta: Que tenho capacidade para trabalhar.

Questão: Se um amigo ou familiar estivesse na mesma situação que você, que conselho lhe daria?

Possível resposta: Que não desistisse.

Questão: E o que devemos fazer?

Possível resposta: Procurar outro emprego.

Questão: Como se sente agora?

Possível resposta: Mais animado.

Esse exemplo traz a construção de uma cadeia de pensamentos, levando o indivíduo a refletir sobre a coerência de suas ideias, que podem estar na raiz de seus sintomas. Ao perceber quais pensamentos estão por trás de determinados sentimentos, o indivíduo começa a educar-se para tentar evitar os pensamentos negativos (BECK, 2007).

Aaron Beck defende que as interpretações negativas do indivíduo sobre si mesmo, o mundo e o futuro explicam a ativação dos sintomas depressivos. Assim, estabelecem-se como pressupostos básicos da depressão, de acordo com o modelo de Beck, a tríade cognitiva e as distorções cognitivas. (POWELL et al, 2008; MARBACK; PELISOLI, 20I4)

Admitir-se a relação entre afeto e cognição, não apenas auxilia na compreensão da depressão, mas também é fundamental na prevenção do suicídio. Isso porque o comportamento suicida, que não se limita ao ato propriamente dito, mas envolve também ideação, planejamento e tentativa, geralmente é motivado por crenças de desesperança. Tais crenças estão diretamente ligadas a um dos pilares da tríade cognitiva da depressão a percepção negativa do futuro. (MARBACK; PELISOLI, 20I4)

Um dos princípios da TCC é o de que é possível monitorar as cognições. Uma estratégia para facilitar a monitoração do pensamento é o Registro de Pensamentos Disfuncionais - RPD. A proposta é que, diante da percepção de humor rebaixado, o indivíduo comece a fazer anotações acerca da situação em que ocorreu a alteração do humor, o pensamento automático ativado no momento e a emoção que esse pensamento elicia. A partir daí, deve-se procurar avaliar as evidências de que o pensamento seja ou não 
verdadeiro, a fim de identificar e nomear as distorções cognitivas que possam estar nele representadas. Com base nessa avaliação, pode-se tentar uma resposta mais adaptativa ao pensamento automático. Espera-se, com isso, reverter o rebaixamento de humor, alterando, portanto, a emoção percebida pelo indivíduo diante da situação denotada, (BECK, 2007; KNAPP; BECK, 2008)

Aplicando-se, simplificadamente, a técnica ao caso, pode-se inferir o seguinte RPD:

\begin{tabular}{|c|c|c|c|}
\hline Situação & Pensamento Automático & Emoção & Distorção Cognitiva \\
\hline $\begin{array}{l}\text { falta de } \\
\text { trabalho }\end{array}$ & $\begin{array}{l}\text { Sou incompetente. } \\
\text { Não posso fazer nada. } \\
\text { Não gostaram do meu } \\
\text { trabalho. } \\
\text { Minha vida acabou. }\end{array}$ & $\begin{array}{l}\text { derrotismo } \\
\text { impotência } \\
\text { vergonha } \\
\text { desesperança }\end{array}$ & $\begin{array}{l}\text { rotulação } \\
\text { polarização } \\
\text { abstração seletiva, leitura } \\
\text { mental } \\
\text { catastrofização }\end{array}$ \\
\hline
\end{tabular}

A relação entre afeto e cognição pode funcionar como reforço recíproco, em que, em caso de distorção, um alimenta o aspecto disfuncional do outro (KNAPP; BECK, 2008). A intervenção por meio do RPD pode interromper esse círculo vicioso, à medida em que se aplique a busca de respostas mais adaptativas diante da situação ativadora.

Enquanto a TCC, de Aaron Beck, trabalha os pensamentos, a TREC, de Ellis, busca intervir no nível nas crenças, que estão na raiz dos pensamentos distorcidos. Considerando a característica de racionalidade ou irracionalidade, a TREC busca trabalhar sobre as crenças irracionais, que levam a pessoa a manter-se em estado de perturbação no presente, a ponto de sofrer disfunções de ordem emocional, cognitiva e/ou comportamental. (DELGADO, 2019)

O modelo $A B C$ pode ser usado na TREC como estratégia de avaliação inicial para a prática terapêutica (MALAGRIS, 2019). A ele, de acordo com Delgado (2019), podem-se acrescentar os elementos $\mathrm{D}$ e E. Por D compreende-se o debate, que deve ser aplicado às crenças, tanto irracionais como racionais do componente $\mathrm{B}$, a fim de verificar se têm sustentação. O efeito da aplicação do debate (D) sobre o sistema de crenças (B) será o componente $\mathrm{E}$, que representa crenças racionais alternativas, que servirão de base para condutas funcionais e emoções saudáveis. (DELGADO, 2019) 
Tomando-se o exemplo explorado no RPD, constrói-se o seguinte modelo de TREC:

\begin{tabular}{|c|c|}
\hline $\begin{array}{l}\text { A } \\
\text { (Evento } \\
\text { Ativador) }\end{array}$ & $\begin{array}{l}\text { Situação: falta de trabalho } \\
\text { Inferência: Não tenho valor. }\end{array}$ \\
\hline $\begin{array}{l}\text { B } \\
\text { (Beliefs: } \\
\text { Crenças) }\end{array}$ & $\begin{array}{l}\text { Demandas: Devo estar sempre empregado. } \\
\text { Catastrofização: Minha vida acabou. } \\
\text { Intolerância a frustração: Não suporto estar desempregado. } \\
\text { Avaliação Global: Sou um incompetente. / O mundo é injusto. }\end{array}$ \\
\hline $\begin{array}{l}\text { C } \\
\text { (Consequências) }\end{array}$ & $\begin{array}{l}\text { Emocional: vergonha, desesperança, depressão } \\
\text { Comportamental: brigar, xingar, agredir } \\
\text { Fisiológica: insônia }\end{array}$ \\
\hline $\begin{array}{l}\mathrm{D} \\
\text { (Debate) }\end{array}$ & $\begin{array}{l}\text { O que o leva a pensar que deve sempre estar empregado? Como você } \\
\text { se sente mantendo esse pensamento? Pensar assim é útil para } \\
\text { resolver o problema? } \\
\text { O que você pode fazer para resolver o problema? Se fosse um amigo } \\
\text { seu que estivesse desempregado, o que diria a ele? }\end{array}$ \\
\hline $\begin{array}{l}\text { E } \\
\text { (Efeito) }\end{array}$ & $\begin{array}{l}\text { Desejos, preferências: Gostaria de estar sempre empregado. } \\
\text { Avaliação moderada do mal: Estar desempregado é ruim, mas não é o } \\
\text { fim da minha vida. } \\
\text { Tolerância a frustração: Estar desempregado é difícil, mas tenho forças } \\
\text { para lutar contra essa situação. } \\
\text { Aceitação incondicional: Perder um emprego não significa que eu não } \\
\text { tenha competência. Ainda que eu não esteja empregado, continuo } \\
\text { tendo valor como ser humano. Mesmo que o mundo não seja justo } \\
\text { como eu gostaria, não significa que seja horrível. }\end{array}$ \\
\hline
\end{tabular}

O questionamento de crenças preconizado pela TREC tende a substituir emoções não saudáveis e disfuncionais por outras, saudáveis e funcionais (DIGIUSEPPE et al, 2014). Aplicando-se ao caso exemplificado, as crenças racionais alternativas gerariam 
substituição da desesperança pela preocupação, da vergonha pelo desconforto, da depressão pela tristeza.

Outra estratégia utilizada em terapia é o uso de metáforas. Renato M. Caminha (2014), em trabalho destinado à educação socioemocional infantil, apresenta a metáfora do barco, que promove a distinção entre o sujeito e suas emoções, capacitando-o a superar os sentimentos negativos e exercitar a resiliência: "Eu sou o barco, não sou a onda. As ondas passam, o barco fica. Por mais que o barco possa ser sacudido por uma onda, essa onda é passageira. Eu não sou aquilo que sinto, eu sou simplesmente a capacidade de sentir." (CAMINHA, 2014)

Em geral, as terapias do escopo cognitivo-comportamental valorizam o que há de positivo na vida do indivíduo, para contrabalancear sua tendência aos pensamentos e crenças negativos. Assim, busca-se recuperar suas memórias agradáveis e habilidades. (BECK, 2007)

No caso do Guerreiro Menino, um aspecto positivo a ser evocado é a existência de um suposto par amoroso, que vem a ser o narrador do texto: uma pessoa que aparentemente lhe tem amor e se preocupa com seu estado emocional. É o que se pode inferir na leitura dos versos: "É triste ver meu homem”, "Eu vejo que ele berra/Eu vejo que ele sangra/A dor que tem no peito/Pois ama e ama” (GONZAGUINHA, 1983).

A TCC considera a importância de se cuidar das relações interpessoais e, particularizando a relação entre casais, aponta para a possibilidade de ajuda mútua como intervenção terapêutica. Além disso, ferramentas como o mindfulness podem compor a terapia, contribuindo para a valorização do parceiro, uma vez que, ao trabalhar a atenção plena, favorece o desenvolvimento da empatia, a identificação e a comunicação das emoções e a regulação das expressões da raiva e ansiedade entre outros aspectos. (DATILLIO, 200I)

As técnicas de relaxamento e meditação sugeridas pelo mindfulness visam à prevenção de reatividade (NEPSIS, 202I). Assim, podem auxiliar no controle da ansiedade, bem como contribuir para a reformulação da tríade cognitiva, uma vez que se promovem a atenção consciente (DATILLIO, 200I). O conforto proporcionado por essas técnicas atende às necessidades expressadas na segunda estrofe do texto, em que se afirma que guerreiros são pessoas comuns, que associam força e fragilidade e, por isso, precisam de 
descanso, de remanso. $\mathrm{O}$ texto informa ainda que, acolhidos em suas necessidades, esses guerreiros são capazes de se recuperar, já que o sono tem o poder de torná-los refeitos. Além disso, supõe-se que o Guerreiro Menino seja dotado de garra para lutar, pois tem motivo para ter esperança, conforme sugere o último verso da terceira estrofe, que reforça que ele "ama e ama".

A capacidade do sujeito de contribuir para a própria recuperação faz parte dos fundamentos da TCC, que se apoia no caráter colaborativo do tratamento. Assim, terapeuta e cliente assumem papéis ativos na reestruturação cognitiva e nas mudanças comportamentais que buscam. (BECK, 2007; KNAPP, 2004b; LEAHY, 2006; WENZEL, 2018)

Por fim, cumpre-se ressaltar que tanto a TCC, de Beck, quanto a TREC, de Ellis, têm por princípio educar psicologicamente o indivíduo, para que, aos poucos, ele se torne seu próprio terapeuta. Entretanto, para que se alcance tal objetivo deve-se buscar uma aliança terapêutica. O primeiro passo para esse intento é dado pelo sujeito que busca ajuda. Cabe, pois, ao terapeuta, prestar-lhe o verdadeiro acolhimento, pautado em escuta atenta, com respeito e empatia. (BECK, 2007; MARBACK; PELISOLI, 2014)

\section{CONSIDERAÇÕES FINAIS}

Ao longo da história, a relação homem-trabalho foi sendo construída como parte da cultura. O trabalho, cujo nome tem origem no castigo corporal - do latim tripalium - e que começou como forma de garantir a subsistência, foi, aos poucos, adquirindo status de valor, passando a ser relacionado à dignidade humana. Por sua vez, a falta de trabalho também vai assumindo sentidos diferentes, de acordo com a visão de mundo que se apresenta em cada época. Quanto mais se valoriza o homem por sua capacidade produtiva, mais se lhe aproxima do comportamento de autodepreciação e do sentimento de desvalia face à falta de trabalho.

A opção pela leitura de um texto poético trouxe a possibilidade de contextualizar o caso em diferentes períodos históricos. Assim, observou que:

I. Na década de 1980, quando o trabalho era visto como dever, estar desempregado equiparava-se a estar em desacordo com a legislação. $O$ conflito do indivíduo formavase em torno do sentimento de indignidade e perda do seu valor enquanto ser humano. 
2. Na virada do século, momento em que o poder de um país é medido com base em sua capacidade de transitar no mundo da informatização, o valor do homem passa a ser considerado a partir de seu nível de conhecimento tecnológico. Essa nova relação de trabalho dá origem ao grupo dos excluídos digitais. Portanto, a perda do trabalho na Era da Informação é tomada como exclusão social, ativando no sujeito, ao mesmo tempo, as crenças de injustiça e incompetência, que podem eliciar sentimentos como revolta, agressividade e vergonha.

3. Do início do ano 2020 até os dias atuais, no contexto da pandemia de Covid-19, em que a crise sanitária agravou os problemas econômicos e sociais em todo o mundo, o trabalho assume, antes de qualquer outro significado, a função de garantir a sobrevivência. Em contrapartida, a falta do trabalho representa a perda do meio de sustento, bem como do sentido da própria vida. Resta ao sujeito desempregado a sensação de impotência, o derrotismo e a desesperança.

Quaisquer que sejam as visões de mundo e de homem, a ausência do trabalho, bem como a precariedade de suas condições, pode impactar no indivíduo em forma de adoecimento, tanto físico quanto psíquico. Para prevenir que sintomas patologizantes se instalem frente ao acontecimento negativo, as terapias do escopo das cognitivocomportamentais oferecem ferramentas eficazes. Tanto a Terapia CognitivoComportamental, de Aaron Beck, quanto a Terapia Racional-Emotiva Comportamental, de Albert Ellis, apresentam-se como possibilidades de ajuda para a reestruturação cognitiva do indivíduo. A TCC, agindo sobre suas distorções de pensamento, e a TREC, trabalhando sobre suas crenças irracionais, são capazes de fornecer estratégias para que o sujeito crie modos alternativos e mais funcionais de reagir aos eventos adversos.

A pesquisa realizada aponta para a ampliação do potencial de contribuição das Terapias Cognitivo-Comportamentais para o cuidado com a saúde psíquica do ser humano. Com este estudo, no entanto, não se encerram as possibilidades de investigação. Ao contrário, expandem-se junto com as necessidades, na medida em que o desenvolvimento natural e cultural da humanidade venha a apresentar novas contingências, gerando, assim, novas demandas. 


\section{REFERÊNCIAS}

A PANDEMIA DAS SOMBRAS: violência doméstica durante a Covid-ı9. Produção: Organização das Nações Unidas. I2 jun. 2020. I vídeo. Disponível em: <https://brasil.un.org/pt-br/node/86or5>. Acesso em: 25/o8/2021.

ANTUNES, Ricardo. Os sentidos do trabalho: Ensaio sobre a afirmação e a negação do trabalho. São Paulo, SP: Boitempo, 2000.

ANTUNES, Ricardo; ALVES, Giovanni. As mutações no mundo do trabalho na era da mundialização do capital. Educ. Soc., Campinas, v. 25, n. 87, p. 335-35I, maio/ago. 2004. Disponível em: 〈https://www.scielo.br/j/es/a/FSqZN 7 YDckXnYwfqSWqgGPp/?lang=pt\&format=pdf $>$ . Acesso em: 04/o6/2021.

APA. American Psychiatric Association. Manual diagnóstico e estatístico de transtornos mentais: DSM-5. 5. ed. Tradução: Maria Inês Corrêa Nascimento et al. Porto Alegre: Artmed, 2014.

ARAÚJO, Romilda Ramos de; SACHUK, Maria Iolanda. Os sentidos do trabalho e suas implicações na formação dos indivíduos inseridos nas organizações contemporâneas. Revista de Gestão USP. São Paulo, v. I4, n. I, p. 53-66, janeiro/março 2007. Disponível em: <https://core.ac.uk/download/pdf/268313506.pdf >. Acesso em 28/04/2021.

BARBOSA, Ana Luíza Neves de HOLANDA; Costa, Joana Simões; HECKSHER, Marcos. Mercado de trabalho e pandemia da covid-ı: Ampliação de desigualdades já existentes? Mercado de Trabalho: conjuntura e análise, n. 69, p. 55-63, 2020. Disponível em: <http://repositorio.ipea.gov.br/bitstream/I1058/ı186/ı/bmt_69_merc detrabalho.pdf $>$. Acesso em: 24/o8/2021. 
BARBOSA, Arianne de Sá; TERROSO, Lauren Bulcão; ARGIMON, Irani Iracema de Lima. Epistemologia da terapia cognitivo-comportamental: casamento, amizade ou separação entre as teorias? Boletim Academia Paulista de Psicologia, v. 34, n. 86, 2014, p. 63-79. São Paulo: Academia Paulista de Psicologia, 2014. Disponível em: 〈https://repositorio.pucrs.br/dspace/bitstream/ro923/9078/2/Epistemologia_da_terapia_co gnitivo_compotamental_casamento_amizade_ou_separacao_entre_as_teorias.pdf $>$. Acesso em: oI/o6/2021.

BARTHES, et al. Análise estrutural da narrativa. Tradução: Maria Zélia Barbos Pinto. 7. ed. Petrópolis, RJ: Vozes, 2oII.

BECK, Judith. Terapia cognitivo-comportamental: teoria e prática. Tradução: Sandra Costa. Porto Alegre: Artmed, 2007.

BOENTE, Alfredo; BRAGA, Gláucia. Metodologia científica contemporânea. Rio de Janeiro: Brasport, 2004.

BRASIL. Constituição da República Federativa do Brasil (1988). Disponível em: <www.planalto.gov.br/ccivil_03/constituicao/ConstituicaoCompilado.htm〉. Acesso em: 2I/04/202I.

BRASIL. Câmara dos Deputados. Constituição do Brasil de 1967 (anais). v. 4. Brasília: 1969. Disponível em: <https://www.senado.leg.br/publicacoes/anais/pdf-digi talizado/Anais_Republica/1967/1967\%20Livro\%206.pdf>. Acesso em: 19/04/2021.

BRASIL. Ministério da Saúde. Conselho Nacional de Saúde. Resolução n. 466, de 12 de dezembro de 2012. Aprova diretrizes e normas regulamentadoras de pesquisas envolvendo seres humanos. Brasília, Diário Oficial da União, 12 dez. 2012. Disponível em: <https://www.gov.br/ebserh/pt-br/ensino-e-pesquisa/pesquisa-clinica/resolucao466.pdf>. Acesso em: 03/o8/2021. 
CAMINHA. Renato M. Educar crianças: as bases de uma educação socioemocional - um guia para pais, educadores e terapeutas. Novo Hamburgo: Sinopsys, 2014.

DATTILIO, FRANK M. Manual de terapia cognitivo-comportamental para casais e famílias. Tradução: Magda França Lopes. Porto Alegre: Artmed, 20oI.

DEJOURS, Christophe. A loucura do trabalho: estudo de psicopatologia do trabalho. Tradução: Ana Isabel Paraguay; Lúcia Leal Ferreira. 6. ed. São Paulo: Cortez; Oboré, 2015.

DELGADO, Guilherme C. O setor de subsistência na economia brasileira: gênese histórica e formas de reprodução. In: JACCOUD, L. (Org.). Questão social e políticas sociais no Brasil contemporâneo. Brasília: IPEA, 2005. Disponível em: 〈http://repositorio.ipea.gov.br/bitstream/II058/3234/I/Livro_Questao_Social.pdf\#page=91 >. Acesso em: 16/05/2021.

DELGADO, Natália Ferrero. Bases teóricas, princípios e conceitos fundamentais. In: LIPP, Marilda Emmanuel Novaes; LOPES, Tátila Martins; SPADARI, Gabriela Fabbro (Org.). Terapia racional-emotiva comportamental na teoria e na prática clínica. Novo Hamburgo: Sinopsys, 2019.

DIGIUSEPPE, R.; DOYLE, K.; DRYDEN, W.; BACK, W. A practitioner's guide to rational emotive behavioh therapy. 3. ed. Oxford: Oxford University Press, 2014.

ENGELS, Friedrich. (1876). Sobre o papel do trabalho na transformação do macaco em homem. Disponível em: 〈http://www.dominiopublico.gov.br/download/te xto/cvoooo4I.pdf >. Acesso em: 29/04/2021.

GÓES, Geraldo Sandoval; MARTINS, Felipe dos Santos; NASCIMENTO, José Antônio Sena do. Potencial de teletrabalho na pandemia: um retrato no Brasil e no mundo. Carta de $\begin{array}{lllll}\text { Conjuntura, } & \text { n. } & \text { 2020. } & \text { Disponível }\end{array}$ 
$<$ http://repositorio.ipea.gov.br/bitstream/ı1058/ı152/ı6/CC_47_nt_potencial_de_teletrabal ho.PDF >. Acesso em: 24/o8/2021.

IBGE. Desemprego. Rio de Janeiro: IBGE, 20гra. Disponível em: 〈https://www.ibge.gov.br/explica/desemprego.php>. Aceso em: 03/o6/2021.

IBGE. Pesquisa nacional por amostra de domicílios contínua: PNAD Contínua. Rio de Janeiro: IBGE, 202Ib. Taxa de desocupação. Disponível em: <https://agenciadenoticias.ibge.gov.br/agencia-noticias/2012agenciadenoticias/noticias/30793-desemprego-chega-a-I4-7-no-primeiro-trimestre-maiordesde-2012-e-atinge-I4-8-milhoes-de-pessoas $>$. Acesso em: 03/o6/2021.

KNAPP, Paulo. Principais técnicas. In: KNAPP, Paulo. (Org.) Terapia CognitivoComportamental na Prática Psiquiátrica. Porto Alegre: Artmed, 2004a.

KNAPP, Paulo. Princípios fundamentais da terapia cognitiva. In: KNAPP, Paulo. (Org.) Terapia Cognitivo-Comportamental na Prática Psiquiátrica. Porto Alegre: Artmed, 2004b.

KNAPP, Paulo; BECK, Aaron T. Fundamentos, modelos conceituais, aplicações e pesquisa da terapia cognitiva. Rev. Bras. Psiquiatr., v. 30, Supl. II, 2008, p. 54-64.

KOHN, Karen; MORAES, Cláudia Herte de. O impacto das novas tecnologias na sociedade: conceitos e características da sociedade da informação e da sociedade digital. In: XXX Congresso Brasileiro de Ciências da Comunicação. 29 de agosto a 2 de setembro de 2007. Santos: Intercom, 2007.

LEAHY, ROBERT L. Técnicas de terapia cognitiva: manual do terapeuta. Tradução: Maria Adriana V. Veronese, Luzia Araújo. Porto Alegre: Artmed, 2006.

MALAGRIS, Lucia Emmanoel Novaes. Técnicas de intervenção. In: LIPP, Marilda Emmanuel Novaes; LOPES, Tátila Martins; SPADARI, Gabriela Fabbro (Org.). Terapia 
racional-emotiva comportamental na teoria e na prática clínica. Novo Hamburgo: Sinopsys, 2019 .

MARBACK, Roberta Ferrari; PELISOLI, Cátula. Terapia cognitivo-comportamental no manejo da desesperança e pensamentos suicidas. Rev. bras. ter. cogn. v. Io, n. 2, p. I22129, dez. 2014. Rio de Janeiro, 2004. Disponível em: $<$ http://pepsic.bvsalud.org/scielo.php?script=sci_arttext $\&$ pid=Si $80856872014000200008 \& \ln$ $\mathrm{g}=\mathrm{pt} \& \mathrm{nrm}=$ isso $>$. Acesso em: 26/o8/2021.

MATTOS, Viviann Rodriguez. O trabalho na era da globalização: passos para a escravidão. Revista Jus Navigandi, ano 9, n. 226, ig fev. 2004. Teresina: 2004. Disponível em: 〈https://jus.com.br/artigos/4845〉. Acesso em: 08/o6/2021.

MINAYO, Maria Cecília de Souza (org.). Pesquisa social: teoria, método e criatividade. i8 ed. Petrópolis: Vozes, 200I.

MOW. Meaning of Work Internacional Research Team. The meaning of working. London: Academic Press, 1987.

NEPSIS. Núcleo de Pesquisa em Saúde e Uso de Substâncias. Prevenção de reatividade baseada em mindfulness (MBRP). São Paulo: Universidade Federal de São Paulo, 202I. (apostila de curso)

PASQUALOTTI, Adriano. A ética na pesquisa: um procedimento metodológico indispensável. Disponível em: 〈http://usuarios.upf.br/ pasqualotti/etica.htm〉. Acesso em: 30/07/2021.

PEREIRA, Josecleto Costa de Almeida. Os paradigmas no mundo do trabalho na era da globalização. Revista Sequência, n. 46, p. 51-75, jul. 2003. 
PIRES, Guilherme Nunes. Pandemia de covid-I9, crise do capitalismo e neoliberalismo. In: SILVA, João Victor Souza da (Org.). Covid-rg: aspectos socioeconômicos da crise. I. ed. Bauru, SP: Gradus Editora, 2020, p. 43-6r.

POWELL, Vânia Bitencourt; ABREU, Neander; OLIVEIRA, Irismar Reis de; SUDAK, Donna. Terapia cognitivo comportamental da depressão. Rev. Bras. Psiquiatr. v. 30 (supl. II), p. 73-8o, 2008 .

SANTOS, Milton. Por uma outra globalização: do pensamento único à consciência universal. 5. ed. Rio de Janeiro: Record, 20or.

SENA, Max Emiliano da Silva. A força normativa do valor social do trabalho. Rio de Janeiro: Lumen Juris, 2019.

TAVARES, Hênio. Teoria literária. 2. ed. Belo Horizonte: Bernardo Álvares, 1966.

TODOROV, Tzvetan. As estruturas narrativas. Tradução: Leyla Perrone-Moisés. 5. ed. São Paulo: Perspectivas, 2008.

TOFFLER, Alvin. A terceira onda: a morte do industrialismo e o nascimento de uma nova civilização. Tradução: João Távora. I5. Ed. Rio de Janeiro: Records, I980.

TOLFO, Suzana da Rosa; PICCININI, Valmíria. Sentidos e significados do trabalho: explorando conceitos, variáveis e estudos empíricos brasileiros. Psicologia \& Sociedade. v. 19, edição especial I: 38-46, 2007. Disponível em: <https://www.scielo.br/j/psoc/a/GnLRwtX 3 KcddXXjnJ8LgRWy/?lang=pt\&format=pdf Acesso em: 24/o8/2021. 
TRABALHO. In: Dicionário etimológico: etimologia e origem das palavras. 7Graus, 20082021. Disponível em: 〈https://www.dicionarioetimologico.com.br/trabalho/>. Acesso em: $28 / 04 / 2021$.

Um homem também chora. Compositor: Luiz Gonzaga Jr. (Gonzaguinha). Alô, alô, Brasil. Gravadora: EMI-Odeon. Catálogo 064 422930. Ano: 1983. LP/CD.

VIGOTSKI, Lev Semenovitch. (1930). A transformação socialista do homem. Tradução: Roberto Della Santa Barros. Revisão: Marcelo Dalla Vecchia. Disponível em: $\langle$ http://www.estmir.net/1sv_1930_2--_trans-socialista_b.pdf . Acesso em: I6/o5/202I.

WENZEL, Amy. Inovações em terapia cognitivo-comportamental: intervenções estratégicas para uma prática criativa. Porto Alegre: Artmed, 2018.

WHO. World Health Organization. Cronograma: resposta COVID-i9 da OMS.

Disponível em: 〈https://www.who.int/emergencies/diseases/novel-coronaviruszor9 509 /interactive-timeline\#event-71>. Acesso em: 04/o6/2021. 